\title{
Inter-Ocular Symmetry of Vascular Density and Retinal Thickness in Unilateral Anisometropic Amblyopia
}

This article was published in the following Dove Press journal: Clinical Ophthalmology

\section{Zerrin Bayraktar \\ Seren Pehlivanoglu \\ Sukru Bayraktar \\ Sinan Albayrak \\ Muharrem Karakaya}

Department of Ophthalmology, Ozel Gaziosmanpasa Hospital, Yeni Yuzyil University School of Medicine, Istanbul, Turkey
Correspondence: Zerrin Bayraktar Sahrayicedit Mah, Cami Sok, No. 30 Emintas Camlik Sitesi A, Blok D 10 , Kadıkoy, Istanbul 34734, Turkey Tel +90 53376/8977

Email zerrinbayraktar@yahoo.com
Background: Inter-ocular symmetry of macular vascular anatomy in healthy subjects has been well documented in previous optical coherence tomography angiography (OCTA) studies. In our present study, we have demonstrated that the presence of anisometropic amblyopia in one eye does not alter this unique feature significantly. We investigated whether the presence of unilateral anisometropic amblyopia due to moderate amounts of hyperopia and/or astigmatism would have any significant influence on measurements of retinal thickness (RT) and superficial vessel density (SVD) in adult subjects.

Subjects and methods: In the study group, both eyes of 21 adult subjects with unilateral anisometropic amblyopia were enrolled. Only one eye of an age-matched control group including 33 subjects was randomly selected. RT and SVD were measured in foveal and parafoveal retinal areas and compared in amblyopic eyes, their fellow eyes and in the control group. Inter-ocular symmetry of RT and SVD in amblyopic and fellow eyes were investigated by using correlation analysis.

Results: There were statistically significant inter-ocular correlations of foveal and parafoveal RT in amblyopic and fellow eyes $(P<0.0001$, for both). Foveal and parafoveal RT of the control group were not statistically different from amblyopic eyes $(P=0.072$ and $P=$ 0.46 , respectively). There was no difference between foveal SVD of amblyopic eyes and control group $(P=0.10)$ and a significant inter-ocular correlation was found between amblyopic and fellow eyes $(P=0.029)$.

Conclusion: For our adult subjects, none of the investigated OCTA parameters of the amblyopic eyes were found to be statistically different from those of age-matched controls. The preservation of inter-ocular symmetry in the amblyopic and fellow eyes implies that the influence of anisometropic amblyopia in one eye would be relatively small and negligible on routine OCTA examination.

Keywords: anisometropic amblyopia, hyperopia, optical coherence tomography angiography, inter-ocular symmetry

\section{Introduction}

Optical coherence tomography angiography (OCTA) has become increasingly popular within a relatively short period of time because of its non-invasiveness and ease of application. ${ }^{1-3}$ Quantitative normative databases have been developed and a number of clinical studies were performed in order to assess the inter-individual and inter-ocular variability. Those studies revealed a high correlation and interocular symmetry of the investigated OCTA parameters between fellow eyes. ${ }^{4-11}$ 
Amblyopia is defined as a reduction in visual acuity without any obvious pathology of either retina or optic nerve which cannot be improved with the correction of present refractive error. ${ }^{12,13}$ A number of pathological findings have been reported in the lateral geniculate nucleus of amblyopic animals and humans, however, the presence of any functional or morphological alterations in the retina remains controversial. ${ }^{14-16}$

Any subtle retinal morphologic/vascular alterations which could be associated with amblyopia have been investigated by OCT and OCTA. The majority of those studies have failed to demonstrate any significant changes as compared with healthy controls, ${ }^{17-21}$ while increase of macular thickness, ${ }^{22-28}$ reduction of vascular density and enlargement of foveal avascular zone have been reported in some of them. ${ }^{29-31}$

In our present OCTA study, we planned to investigate the macular morphology and vascular network by using retinal thickness and superficial vessel density parameters in the foveal and parafoveal areas of adult subjects with anisometric amblyopia and compared with an age-matched control group. We also made inter-ocular comparisons of amblyopic and fellow eyes in order to investigate whether any inter-ocular symmetry has been present or not.

\section{Methods}

\section{Subjects}

Twenty-one subjects older than 18 years with unilateral hyperopic anisometropic amblyopia were selected for the study group. Patients with any systemic or ocular disease other than amblyopia such as strabismus, nystagmus, media opacity, optic disc pathology, retinal diseases and/or glaucoma were excluded. Subjects with poor gaze-fixation were excluded. Patients with neurologic diseases were also excluded.

Study group included 21 patients, 10 males and 11 females. Mean age was $42.1 \pm 10.6$ years. A total of 33 subjects older than 18 years without any significant ocular pathology and with normal visual acuity were selected as a control group; there were 11 males and 22 females and mean age was $43.4 \pm 6.6$ years. In the study group, both amblyopic and fellow eyes were included, but only one eye was randomly selected in the control group. The research followed the tenets of the Declaration of Helsinki and written informed consent was obtained from all subjects. An approval from Yeni Yuzyil University
Ethical Committee was also obtained (Approval no. 26/ 02/2019-005).

\section{Refraction and Visual Acuity Testing}

A complete ophthalmological examination including slitlamp biomicroscopy, intraocular pressure measurement, fundus examination following pupillary dilation and cycloplegic refraction for the assessment of full refractive error have been performed in all subjects. Spherical and cylindrical refraction (in minus cylinders) were obtained and spherical equivalent was calculated. Visual acuity testing was performed by using standard Snellen chart at $6 \mathrm{~m}$ and converted to $\log$ MAR scale for statistical analysis. Anisometropic amblyopia was defined as at least three lines of reduction of best-corrected visual acuity (BCVA) on Snell chart.

\section{OCTA Imaging}

We used RTVue XR Avanti Optical Coherence Tomography Angiography (Optovue Inc. Fremont California, USA) device. OCTA images were obtained by using automatic setting, AngioVue 3D Retina mode and $3 \times 3 \mathrm{~mm}$ scan size. If the Signal Strenght Indicator (SSI) was turned into red, the operator would switch to the manual setting. The instrument uses a segmentation algorithm which divides full-thickness retinal scans into four segments; the "superficial" and "deep" inner retinal vessel plexuses, outer retina, and choriocapillaris. Segmentation of the superficial inner retina contains the vasculature of the retinal nerve fiber layer and ganglion cell layer. Vascular density values were calculated for foveal and parafoveal macular areas separately.

The foveal region was defined as a circular area of approximately $1 \mathrm{~mm}$ diameter at the center of the fovea and parafoveal region was defined as $2 \mathrm{~mm}$ wide ring surrounding this foveal region. Scans with poor quality and/or double vessel pattern, blink artifacts, signal strength index less than 50 were discarded, and additional OCTA scans with sufficient quality were obtained.

\section{Data Collection and Statistical Analysis}

The retinal thickness and superficial vascular density values obtained at the foveal and parafoveal macular regions were used for the study. SPSS version 22 (SPSS, Inc, Chicago, Illinois, USA) was used for statistical analysis. Wilcoxon Signed Ranks test was used for investigating the inter-ocular differences between amblyopic and fellow eyes. Mann-Whitney $U$-test was used for analyzing 
the differences between the amblyopic eyes and the control group. Any possible correlation between retinal thickness, superficial retinal vascular density and refraction was investigated by using Spearman Correlation test.

\section{Results}

\section{Visual Acuity and Refraction}

Average BCVA was $0.37 \pm 0.20 \log$ MAR (Snellen equivalent of approximately 20/50) in the amblyopic eyes. By definition; all of the eyes in the control group and fellow eyes of the amblyopic patients had a BCVA of 20/20 Snellen.

The refraction of the subjects was shown in Table 1. In all three groups, mean spherical and spherical equivalent refractions were hyperopic. Average spherical equivalent refraction was $+2.09 \pm 2.91 \mathrm{D}$ in the amblyopic eyes, $+0.70 \pm 1.48 \mathrm{D}$ in their fellow eyes and $+0.16 \pm 0.41$ $\mathrm{D}$ in the control eyes. As expected, more hyperopia $(P<$ $0.0001)$ and astigmatism $(P<0.0001)$ were present in the amblyopic eyes as compared with their fellow eyes. The least amount of hyperopia $(P<0.0001)$ and astigmatism $(P<0.0001)$ were present in the control group.

\section{Retinal Thickness}

Average of the measurements obtained from foveal and parafoveal retinal regions is shown in Table 2.

The difference between average foveal retinal thickness measurements of the amblyopic eyes and control group was not statistically significant $(P=0.072)$. There was no statistically significant difference between amblyopic and fellow eyes $(P=0.50)$ and a statistically significant positive interocular correlation was found $(r=0.98, P<0.0001$, Figure 1$)$.

In the amblyopic eyes, average parafoveal retinal thickness was significantly greater than the control group $(P=$ 0.006). There was no statistically significant difference between amblyopic and fellow eyes $(P=0.092)$ and

Table I Refraction Data in the Study and Control Groups

\begin{tabular}{|l|l|l|l|}
\hline & $\begin{array}{l}\text { Amblyopic } \\
\text { Eyes } \\
\text { (Study } \\
\text { Group) }\end{array}$ & $\begin{array}{l}\text { Fellow Eyes } \\
\text { (Study } \\
\text { Group) }\end{array}$ & $\begin{array}{l}\text { Control } \\
\text { Group }\end{array}$ \\
\hline $\begin{array}{l}\text { Spherical } \\
\text { refraction (D) } \\
\text { Cylindrical } \\
\text { refraction (D) } \\
\begin{array}{l}\text { Spherical } \\
\text { equivalent (D) }\end{array}\end{array}$ & $+3.17 \pm 2.53$ & $+1.00 \pm 1.43$ & $+0.30 \pm 0.45$ \\
\hline
\end{tabular}

Abbreviation: D, diopters.
Table 2 Retinal Thickness and Superficial Vascular Density

\begin{tabular}{|l|l|l|l|}
\hline & $\begin{array}{l}\text { Amblyopic } \\
\text { Eyes } \\
\text { (Study } \\
\text { Group) }\end{array}$ & $\begin{array}{l}\text { Fellow Eyes } \\
\text { (Study } \\
\text { Group) }\end{array}$ & $\begin{array}{l}\text { Control } \\
\text { Group }\end{array}$ \\
\hline $\begin{array}{l}\text { Foveal RT } \\
(\mu \mathrm{m})\end{array}$ & $255.62 \pm 19.42$ & $251.76 \pm 19.53$ & $247.64 \pm 17.05$ \\
$\begin{array}{l}\text { Parafoveal RT } \\
(\mu \mathrm{m})\end{array}$ & $328.24 \pm 14.93$ & $324.48 \pm 17.08$ & $316.00 \pm 14.37$ \\
$\begin{array}{l}\text { Foveal SVD } \\
(\%)\end{array}$ & $31.26 \pm 5.64$ & $31.27 \pm 6.52$ & $28.82 \pm 4.54$ \\
$\begin{array}{l}\text { Parafoveal } \\
\text { SVD (\%) }\end{array}$ & $51.66 \pm 6.10$ & $51.23 \pm 6.39$ & $53.36 \pm 4.07$ \\
\hline
\end{tabular}

Abbreviations: RT, retinal thickness; SVD, superficial vascular density.

a statistically significant positive inter-ocular correlation was present ( $r=0.85, P<0.0001$, Figure 1).

There were no statistically significant correlation between spherical equivalent refraction with either foveal RT $(r=0.038, P=0.87)$ or parafoveal RT $(r=0.013, P=$ $0.96)$ in the amblyopic eyes.

\section{Retinal Vascular Density}

Average of the measurements obtained from foveal and parafoveal retinal areas ie shown in Table 2.

Averages of superficial foveal vascular density measurements in the amblyopic eyes and control group were not statistically different $(P=0.10)$. There was no statistically significant difference between amblyopic eyes and their fellows $(P=0.74)$ and a statistically significant positive interocular correlation was found ( $r=0.48, P=0.029$, Figure 2$)$.

Averages of the superficial parafoveal vascular density measurements of amblyopic eyes and control group were not statistically different $(P=0.37)$. Fellow eyes measurements were not statistically different than the amblyopic eyes $(P=0.90)$. However, the inter-ocular correlation between amblyopic and fellow eyes was not statistically significant ( $r=0.23, P=0.31$, Figure 2 ).

In the amblyopic eyes, there were no statistically significant correlation between spherical equivalent of refraction with either foveal $(r=0.36, P=0.11)$ or parafoveal superficial vascular density $(r=0.04, P=0.86)$.

In amblyopic eyes, there was a significant positive correlation between the retinal thickness and superficial vascular density in the fovea $(r=0.44, P=0.044$, Figure 3$)$. In the control group, a similarly statistically significant positive correlation was found between retinal thickness and superficial vascular density in the foveal area $(r=0.51, P=0.02$, Figure 3). 


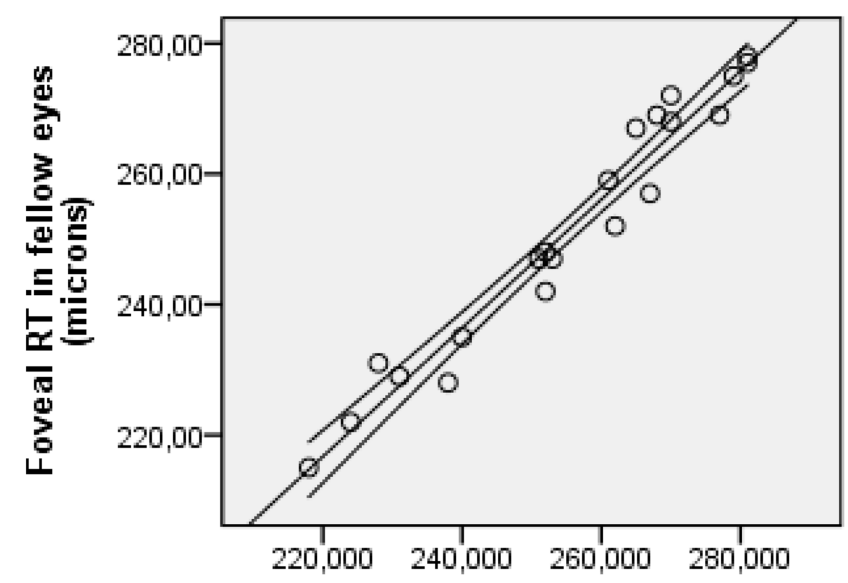

Foveal RT in amblyopic eyes (microns)

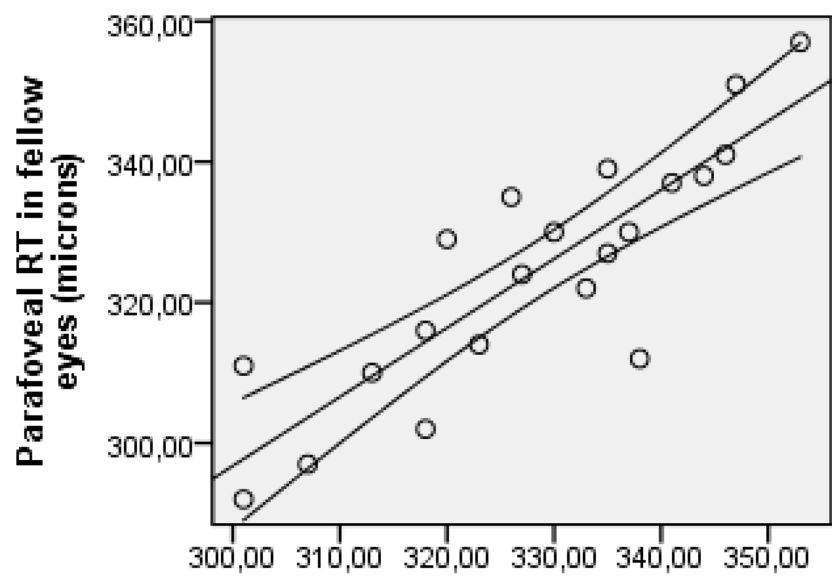

Parafoveal RT in amblyopic eyes (microns)

Figure I Inter-ocular correlation of retinal thickness of amblyopic and fellow eyes in foveal $\left(r^{2}=0.96\right)$ and parafoveal $\left(r^{2}=0.74\right)$ areas Abbreviation: RT, retinal thickness.

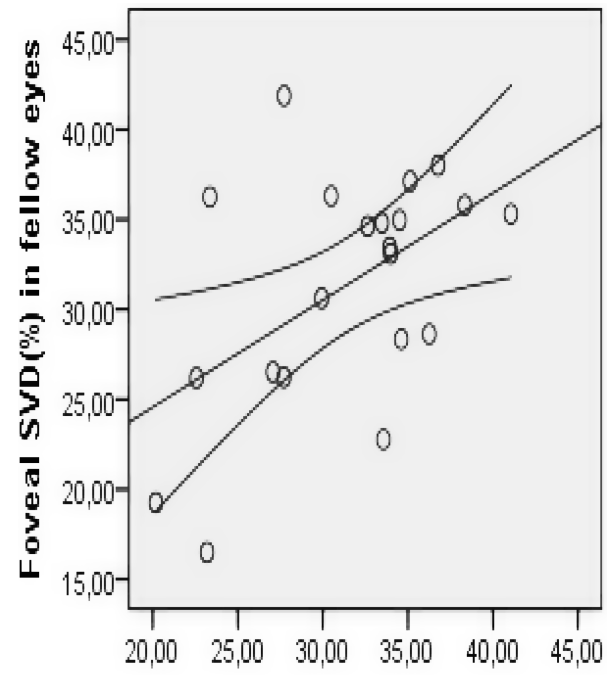

Foveal SVD(\%) in amblyopic eyes

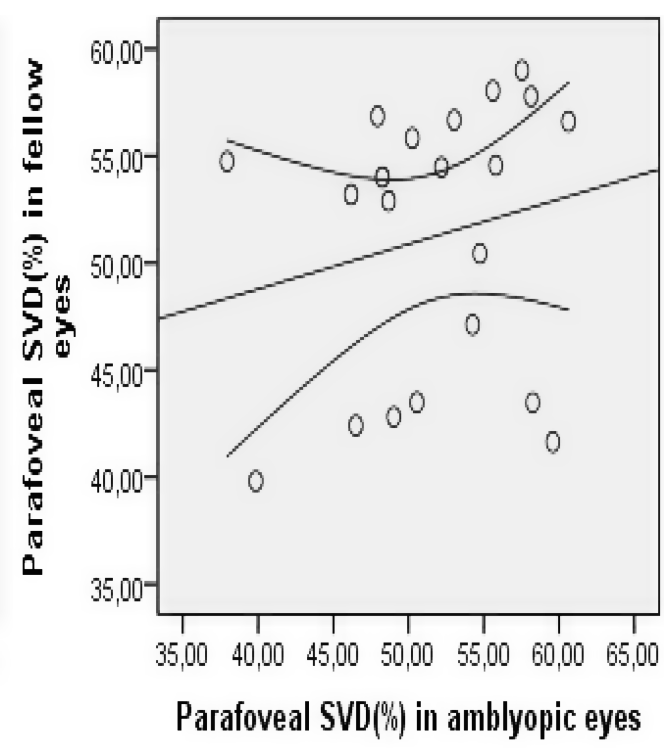

Figure 2 Inter-ocular correlation of vascular density in superficial retinal plexus of amblyopic and fellow eyes in foveal $\left(r^{2}=0.27\right)$ and parafoveal $\left(r^{2}=0.04\right)$ areas. Abbreviation: SVD, superficial vascular density.

\section{Discussion}

In our study, we planned to investigate the retinal morphology and vascular network by using OCTA in the macular area of patients with unilateral hyperopic anisometric amblyopia. We selected the superficial capillary plexus for that purpose, as it was shown to be technically much easier and more reproducibly measured than the deep plexus. ${ }^{33} \mathrm{We}$ measured retinal thickness and superficial vascular density at both foveal (approximately $1 \mathrm{~mm}$ in the center) and parafoveal ( $2 \mathrm{~mm}$ wide ring surrounding the former) areas.
Macular vascular alterations in amblyopic eyes of children were investigated by OCTA in a number of previous studies with conflicting results. Lonngi et al found that vascular density was lower in amblyopic eyes as compared with normal controls. ${ }^{29}$ Yilmaz et al and Sobral et al also reported reduced vascular density measurements in the amblyopic eyes. ${ }^{30,31}$ In all of those studies, the authors could not propose any hypothesis in order to explain the clinical relevance of their findings but they recommended that further studies need to be performed. In a recent 


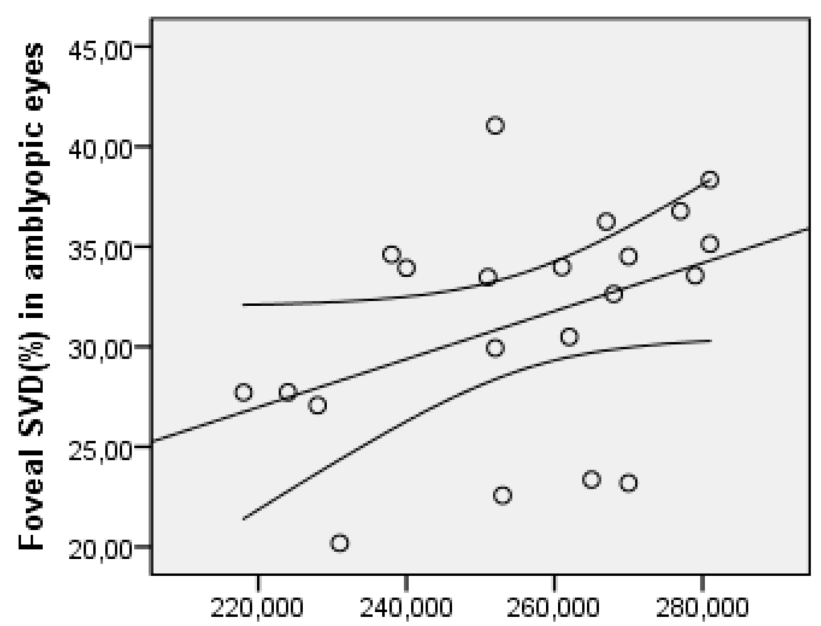

Foveal RT in amblyopic eyes (microns)

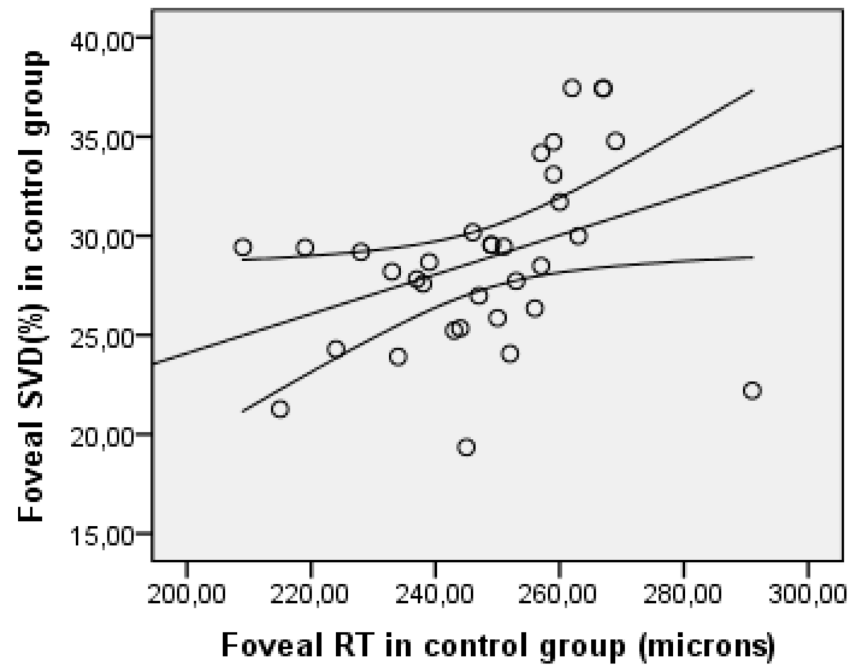

Figure 3 Correlation of foveal retinal thickness and vascular density in amblyopic eyes $\left(r^{2}=0.17\right)$ and in control $\left(r^{2}=0.14\right)$ group. Abbreviations: RT, retinal thickness, SVD, superficial vascular density.

OCTA study, however, Demirayak et al reported that superficial vascular density measurements of the adult amblyopic patients were not statistically different than the age-matched control group. ${ }^{32}$

In contrast to our study population which composed of adult subjects only, all but one of those above studies included children. The influence of age on vascular measurements of OCTA has been shown in some studies; foveal avascular zone was found to be increased and vascular density reduced as the subject gets older. ${ }^{4,9,11}$ In our study, we intended to investigate whether the presence of amblyopia has any influence on OCTA measurements which could have some importance in interpretation of OCTA results in routine clinical settings; therefore, we selected adult patients with amblyopia. In our study, we could not find any statistically significant difference between vascular density measurements of the amblyopic eyes with the age-matched control group.

We found a statistically significant inter-ocular correlation between the foveal vascular density measurements of the amblyopic and fellow eyes. The inter-ocular symmetry of macular vascular anatomy has been well documented in healthy subjects and normative database OCTA studies. ${ }^{3,6-8}$ On the other hand, the inter-ocular correlation of parafoveal vascular density between amblyopic and fellow eyes was weaker. We think that it was not statistically significant because of the higher variability. The higher repeatability of foveal measurements over parafoveal ones was also shown in previous studies. ${ }^{7}$
Another important aspect of our study is the inclusion of retinal thickness measurements in addition to vascular density. Despite the presence of amblyopia, the retinal thickness measurements obtained at foveal and parafoveal retinal areas of the fellow eyes showed a highly significant inter-ocular symmetry.

In our study, we found statistically significant positive correlations between foveal retinal thickness and vascular density both in the amblyopic eyes and control groups. The positive relationship between retinal thickness and vascular density has been well documented in numerous previous studies of normal subjects. ${ }^{5,6,9,10}$ We think that the preservation of the correlation between the retinal thickness and vascular density in amblyopic eyes is clinically important.

In the previous studies, total retinal thickness and retinal nerve fiber layer thickness have shown to be positively correlated with the refraction and/or axial length. The axial magnification of the OCT device has been thought to be responsible for this phenomena and correction by using some formulas have been suggested in eyes with high ametropias. ${ }^{34,35}$ Correction of magnification error has also been studied in some OCTA studies with somehow confusing results. ${ }^{7,10}$ In our study, we did not make any axial length measurements, but only investigated the correlation between spherical equivalent refraction with retinal thickness and vascular density. We were not able to demonstrate any statistically significant correlation between them, however. In our study, the average hyperopia in amblyopic eyes was moderate - only about two 
diopters; thus the inclusion of eyes with higher hyperopic error could have changed our results.

In summary, we were unable to demonstrate any statistically significant differences of retinal thickness and vascular density measurements obtained from adult subjects with moderate unilateral hyperopic anisometropic amblyopia in our age-matched and fellow eye-controlled study. We think that the preservation of inter-ocular correlation despite the presence of amblyopia is clinically important and fellow eye data can be used as a control measure in cases of clinical suspicion. We suggest that during routine clinical OCTA practice, the influence of moderate unilateral hyperopic anisometropic amblyopia on retinal vascular density measurements is relatively small and negligible.

\section{Author Contributions}

Conceptualization: ZB, SP, data curation: ZB, SP, formal analysis: ZB, SP, investigation: ZB, SP, SA, MK, methodology: SP, SA, MK, supervision: SB, validation: SP, writing of original draft: $\mathrm{ZB}, \mathrm{SP}, \mathrm{SB}$, writing, review and editing: $\mathrm{ZB}$, SB. All authors contributed to data analysis, drafting or revising the article, gave final approval of the version to be published, and agree to be accountable for all aspects of the work.

\section{Disclosure}

There are no conflicts of interest associated with this work for any of the authors.

\section{References}

1. Spaide RF, Klancnik JM, Cooney MJ. Retinal vascular layers in macular telangiectasia imaged by fluorescein angiography and optical coherence tomography angiography. JAMA Ophthalmol. 2015;133:66-73. doi:10.1001/jamaophthalmol.2014.3950

2. Savastano MC, Lumbroso B, Rispoli M. In vivo characterization of retinal vascularization morphology using optical coherence tomography angiography. Retina. 2015;35:2196-2203. doi:10.1097/ IAE. 0000000000000635

3. Shahlaee A, Samara WA, Hsu J, et al. In vivo assessment of macular vascular density in healthy human eyes using optical coherence tomography angiography. Am J Ophthalmol. 2016;165:39-46. doi:10.1016/ j.ajo.2016.02.018

4. Coscas F, Sellam A, Glaced-Bernard A, et al. Normative data for vascular density in superficial and deep capillary plexuses of healthy adults assessed by optical coherence tomography angiography. Invest Ophthalmol Vis Sci. 2016;57(9):211-223. doi:10.1167/iovs.15-18793

5. Yu J, Gu R, Zong Y, et al. Relationship between retinal perfusion and retinal thickness in healthy subjects: an optical coherence tomography angiography study. Invest Ophthalmol Vis Sci. 2016;57:204-210. doi:10.1167/iovs.15-18630

6. Liu G, Keyal K, Wang F. Interocular symmetry of vascular density and association with central macular thickness of healthy adults by optical coherence tomography angiography. Sci Rep. 2017;7:16297. doi:10.1038/s41598-017-16675-w
7. Chen FK, Menghini M, Hansen A, et al. Intrasession repeatability and interocular symmetry of foveal avascular zone and retinal vessel density in OCT Angiography. Transl Vis Sci Technol. 2018;7:6. doi:10.1167/tvst.7.1.6

8. Fang D, Tang FY, Huang H, et al. Repeatability, interocular correlation and agreement of quantitative swept-source optical coherence tomography angiography macular metrics in healthy subjects. $\mathrm{Br}$ J Ophthalmol. 2018;103:415-420. doi:10.1136/bjophthalmol-2018311874

9. Falavarjani KG, Shenazandi H, Naseri D, et al. Foveal avascular zone and vessel density in healthy subjects: an optical coherence tomography angiography study. J Ophthalmic Vis Res. 2018;13:260-265. doi:10.4103/jovr.jovr_173_17

10. Hassan M, Sadiq MA, Halim MS, et al. Evaluation of macular and peripapillary vessel flow density in eyes with no known pathology using optical coherence tomography angiography. Int $J$ Retina Vitreous. 2017;3:27. doi:10.1186/s40942-017 $-0080-0$

11. Leng Y, Tam EK, Falavarjani KG, Tsui I. Effect of age and myopia on retinal microvasculature. Ophthalmic Surg Lasers Imaging Retina. 2018;49:925-931. doi:10.3928/23258160-20181203-03

12. Day S. Normal and abnormal visual development. In: Taylor D, editor. Pediatric Ophthalmology. London: Blackwell Scientific; 1990:7-20.

13. Weakley DR Jr. The association between nonstrabismic anisometropia, amblyopia and subnormal binocularity. Ophthalmology. 2001;108:163-171. doi:10.1016/S0161-6420(00)00425-5

14. Liu H, Zhong L, Zhou X, Jin QZ. Macular abnormality observed by OCT in children with amblyopia failing to achieve normal visual acuity after long term treatment. J Pediatr Ophthalmol Strabismus. 2010;47:17-23. doi:10.3928/01913913-20091019-06

15. Arden GB, Wooding SL. Pattern ERG in Amblyopia. Invest Ophthalmol Vis Sci. 1985;26:88-96.

16. Delint PJ, Weissenbruch C, Berendschot TT, Norren DV. Photoreceptor function in unilateral amblyopia. Vision Res. 1998;38:613-617. doi:10.1016/S0042-6989(97)00191-0

17. Yalcin E, Balci O. Peripapillary retinal nerve fiber layer and foveal thickness in hyperopic anisometropic amblyopia. Clin Ophthalmol. 2014;12:749-753.

18. Firat PG, Ozsoy E, Demirel S, et al. Evaluation of peripapillary retinal nerve fiber layer, macula and ganglion cell thickness in amblyopia using spectral optical coherence tomography. Int $J$ Ophthalmol. 2013;6:90-94. doi:10.3980/j.issn.22223959.2013.01.19

19. Walker RA, Rubab S, Voll ARL, et al. Macular and peripapillary retinal nerve fiber layer thickness in adults with amblyopia. Can J Ophthalmol. 2011;46:425-427. doi:10.1016/j.jcjo.2011.07.013

20. Kantarci FA, Tatar MG, Uslu H, et al. Choroidal and peripapillary retinal nerve fiber layer thickness in adults with anisometropic amblyopia. Eur J Ophthalmol. 2015;25:437-442. doi:10.5301/ ejo.5000594

21. Araki S, Miki A, Yamashita T, et al. A comparison between amblyopic and fellow eyes in unilateral amblyopia using spectral-domain optical coherence tomography. Clin Ophthalmol. 2014;8:2199-2207. doi:10.2147/OPTH.S69501

22. Yen MY, Cheng CY, Wang AG. Retinal Nerve Fiber Layer Thickness in Unilateral Amblyopia. Invest Ophthalmol Vis Sci. 2004;45:2224-2230. doi:10.1167/iovs.03-0297

23. Silva F, Alves S, Pina S, et al. Comparison of macular thickness and volume in amblyopic children using time domain optical coherence tomography. Ophthalmology. 2012;36:231-236.

24. Aguirre F, Mengual E, Hueso JR, Moya M. Comparison of normal and amblyopic retinas by optical coherence tomography in children. Eur $J$ Ophthalmol. 2010;20:410-418. doi:10.1177/ 112067211002000223 
25. Repka MX, Goldenberg-Cohen N, Edwards AR. Retinal nerve fiber layer thickness in amblyopic eyes. $\mathrm{Am} J$ Ophthalmol. 2006;142:247-251. doi:10.1016/j.ajo.2006.02.030

26. Bozkurt B, Irkec M, Orhan M, Karaagaoglu E. Thickness of the retinal nerve fiber layer in patients with anisometropic and strabismic amblyopia. Strabismus. 2003;11:1-7. doi:10.1076/stra.11.1.1.14091

27. Rajavi Z, Moghadasifar H, Feizi M, et al. Macular thickness and amblyopia. J Ophthalmic Vis Res. 2014;9:478-483. doi:10.4103/ 2008-322X.150827

28. Andalib D, Javadzadeh A, Nabai R, Amizadeh Y. Macular and retinal nerve fiber layer thickness in unilateral anisometropic or strabismic amblyopia. J Pediatr Ophthalmol Strabismus. 2013;50:218-221. doi:10.3928/01913913-20130319-02

29. Lonngi M, Velez FG, Tsui I, et al. Spectral-domain optical coherence tomographic angiography in children with amblyopia. JAMA Ophthalmol. 2017;135:1086-1091. doi:10.1001/ jamaophthalmol.2017.3423

30. Yilmaz I, Ocak O, Yllmaz B, et al. Comparison of quantitative measurement of foveal avascular zone and macular vessel density in eyes of children with amblyopia and healthy controls: an optical coherence tomography angiography study. $J$ AAPOS 2017;21:224-228. doi:10.1016/j.jaapos.2017.05.002
31. Sobral I, Rodrigues TM, Soares M, et al. OCT angiography findings in children with amblyopia. $J$ AAPOS. 2018;22:286-289. doi:10.1016/j.jaapos.2018.03.009

32. Demirayak B, Vural A, Onur IU, et al. Analysis of macular vessel density and foveal avascular zone using spectral-domain optical coherence tomography angiography in children with amblyopia. J Pediatr Ophthalmol Strabismus. 2018;26:1-5.

33. Durbin MK, An L, Shemonski ND, et al. Quantification of retinal microvascular density in optical coherence tomographic angiography images in diabetic retinopathy. JAMA Ophthalmol. 2017;135:370-376. doi:10.1001/jamaophthalmol.2017.0080

34. Bayraktar S, Bayraktar Z, Yilmaz OF. Influence of scan radius correction for ocular magnification and relationship between scan radius with retinal nerve fiber layer thickness measured by optical coherence tomography. J Glaucoma. 2001;10:163-169. doi:10.1097/ 00061198-200106000-00004

35. Hirasawa K, Shoji N, Yoshii Y, Haraguchi S. Comparison of Kang's and littmann's methods of correction for ocular magnification in circumpapillary retinal nerve fiber layer measurement. Invest Ophthalmol Vis Sci. 2014;55:8353-8358. doi:10.1167/iovs.14-15720
Clinical Ophthalmology

\section{Publish your work in this journal}

Clinical Ophthalmology is an international, peer-reviewed journal covering all subspecialties within ophthalmology. Key topics include: Optometry; Visual science; Pharmacology and drug therapy in eye diseases; Basic Sciences; Primary and Secondary eye care; Patient Safety and Quality of Care Improvements. This journal is indexed on PubMed
Dovepress

Central and CAS, and is the official journal of The Society of Clinical Ophthalmology (SCO). The manuscript management system is completely online and includes a very quick and fair peer-review system, which is all easy to use. Visit http://www.dovepress.com/ testimonials.php to read real quotes from published authors. 